\title{
Karakter Anti-Hero sebagai Counter-Hegemoni Superhero dalam Film Deadpool Analisis Counter-Hegemoni Antonio Gramsci
}

\author{
Muhammad Fathan Zamani ${ }^{1)}$, Abi Ihsanullah ${ }^{2)}$, Badri ${ }^{3)}$ \\ ${ }^{1}$ Fakultas Ilmu Budaya, Universitas Gadjah Mada \\ email: muh.fathan.zamani@mail.ugm.ac.id \\ ${ }^{2}$ Fakultas Ilmu Budaya, Universitas Gadjah Mada \\ email: abiihsanullah@mail.ugm.ac.id \\ ${ }^{3}$ Fakultas Ilmu Budaya, Universitas Gadjah Mada \\ email: badri@mail.ugm.ac.id
}

\begin{abstract}
Myth is an essential part in superhero roles. In modern superhero acts, a character may possess more than one myth. Thus, this portrayal is an ideal power to create supremacy. An author, even a director could employ the newly-created myth to overcome hegemonic power. As stated in Gramsci, there is an instrument to control, even surpass ideology. In the Deadpool $1 \& 2$ movie, the myth of superheroes is interpreted as the instrument of hegemony. The aims of this study are to find out what kind of superhero hegemony that will be countered in the Deadpool movie, what are the counter hegemony element in the Deadpool movie, and how are the Deadpool's effort and his preparations doing ideological battle against the superhero existence. This research uses hegemony and counter-hegemony theory according to Antonio Gramsci. This research applies descriptive qualitative method. The findings are Deadpool's act of violence and his merc-with-mouth assuming his role as an anti-hero. However, Deadpool finally encountered the existing myth of superheroes ideologically. Unexpectedly, Deadpool offers a solution to the existing hegemony.
\end{abstract}

Keywords: Hegemony, Counter-hegemony, Ideology, Deadpool Movie, Antonio Gramsci

\section{Pendahuluan}

Pertarungan ideologi merupakan sebuah keharusan yang menekankan sebagian golongan dengan cara-cara yang dianggap wajar. Sejak zaman dahulu, manusia identik dengan sistem kekuasaan yang menjadikan mereka sebagai The Supreme atau golongan atas yang berusaha untuk menciptakan realita-realita semenjana bagi subordinatnya. Hal ini tidak 
terlepas dari tindakan yang dilakukan dengan cara-cara terstruktur tanpa menimbulkan kerusakan yang masif dalam sebuah kebudayaan. Salah satu media yang menunjukkan supremasi tersebut adalah karya sastra.

Kajian kesusastraan tidak hanya menggambarkan tentang bagaimana kita melihat sebuah wacana di dalam sebuah karya melainkan juga untuk melihat konsepsi sosial-politik yang terjadi dibalik karya tersebut. Dengan demikian, dapat ditemukan unsur-unsur ideologis yang melingkupi masyarakat pada periode tertentu. Ini merupakan akibat dari permainan politik yang kerap terjadi dimana karya sastra dijadikan sebuah bahan kritik hingga parodi terhadap rezim yang sedang berkuasa.

Deadpool merupakan sebuah film yang menceritakan tentang karakter Deadpool yang diperankan oleh Ryan Reynolds, sosok anti-hero yang diadaptasi oleh rumah produksi $20^{\text {th }}$ Century Fox dari komik Marvel pada tahun 2016. Deadpool dalam film ini merupakan rekayasa genetika dari seorang karakter villain bernama Ajax atau Francis. Wilson yang memiliki penyakit kanker menerima suntikan yang dapat membangkitkan gen mutant. Suntikan ini menciptakan perubahan yang menakjubkan sekaligus memberinya kekuatan penyembuhan yang luar biasa dari dalam tubuhya sendiri. Jika anggota tubuh Wilson terluka, maka dia dapat melakukan self-healing dengan cepat. Self-healing itu juga dapat menyembuhkan kankernya. Namun, Wilson mengalami luka bakar di sekujur tubuhnya. Ajax menenangkan Wilson dengan berbohong bahwa luka bakar itu dapat disembuhkan. Dia meninggalkan Wilson di dalam laboratorium yang akan meledak.

Wilson meminta bantuan kepada satu-satunya orang yang dia percaya yaitu Vanessa. Namun, dia tidak memberi tahu siapa dirinya karena khawatir akan kondisi tubuhya yang sangat buruk. Dengan berbekal topeng, Wilson kemudian bertansfromasi menjadi seorang Vigilante dan mulai menebar terror terhadap para penjahat. Meski demikian tindakannya bertentangan dengan tujuan X-men, dimana menurut Colossus, tindakan superhero adalah menghakimi penjahat dengan hukum yang berlaku. Namun, dengan wujud Deadpool-nya, Wilson tidak menerima pendapat Colossus. Bahkan dia melawan Colossus karena dia merasa tidak pernah menjadi bagian dari X-men. Deadpool pada akhirnya berhasil mengalahkan semua musuhnya dengan konsekuensi yang sangat besar; pikiran dan tubuhnya menunjukkan gejala kronis. Pikiran Wilson terbagi antara penyakit yang terus menghabisi tubuhnya dan keinginannya mencipatakan dunia seperti yang dia impikan.

Film Deadpool mempermasalahkan hegemoni superhero yang bertahan lama sehingga menciptakan kebosanan dalam penyajiannya di hadapan para penonton. Film-film seperti Spiderman, Captain America, dan Iron Man dianggap hanya pengulangan dari 
formula- formula film Superhero sebelumnya. Para pemilik rumah produksi dituntut untuk menciptakan alur yang berbeda; masyarakat menyinggung politik dan menuntut realitas sesuai dengan kondisi sosial masa kini. Hal ini tampak dari munculnya berbagai tokoh antihero dalam film maupun serial TV: Deadpool, Ghost Rider, Blade, Cable, Rorschachs Watchmen, Harley Quinn, Deadshot, John Constantine, dan beberapa karakter lainnya.

Munculnya anti-hero sebagai counter-hegemoni merupakan hasil dari meningkatnya kemarahan pembaca dan desensitisasi terhadap kekerasan yang meningkat seiring berjalannya waktu. Kekerasan dijadikan sebuah alat untuk melawan kemapanan yang selama ini selalu meninggalkan celah dari realitas yang ada. Disinilah peran anti-hero dimana mereka memiliki dunia yang terbebas dari hegemoni superhero yang selalu membelenggu tindakan mereka. Maka timbul beberapa anomali karakter seperti pelanggar hukum yang romantis, pembunuh yang sayang keluarga, pecandu narkoba yang melindungi masyarakat, dan lain- lain.

Penelitian ini bertujuan untuk mengungkapkan hegemoni superhero yang akan dicounter di dalam Film Deadpool, unsur-unsur counter-hegemoni yang dimiliki oleh Deadpool dan bagaimana usaha-usaha yang dilakukan oleh Deadpool dalam melakukan pertarungan ideologi terhadap kemapanan superhero. Penelitian ini menggunakan objek materia berupa Film Deadpool dan objek forma berupa teori hegemoni dan counterhegemoni milik Antonio Gramsci. Melalui penelitian ini, diharapkan kritik sastra yang berkenaan dengan adaptasi komik ke dalam film, akademisi lebih memperhatikan telaah kritis daripada sekedar narasi deskriptif, memperkaya khazanah kesusastraan yang dianalisis melalui teori-teori politik khususnya hegemoni Antonio Gramsci.

Penelitian ini merujuk pada kajian-kajian yang telah banyak dibahas dalam diskursus perkuliahan. Pertama adalah Swearing Analysis of Characters in Deadpool Movie oleh Wulandari dan Firmawan (2019). Penelitian ini berfokus pada penggunaan "Swearing" yang dilakukan oleh Deadpool di sepanjang filmnya. Kedua adalah Deadpool and the complex 'crisis' of masculinity. In A. J. Carranza (Ed.), Our Fears Made Manifest: Essays on Terror, Trauma and Loss in Film, 1998-2019. Penelitian yang dilakukan oleh Quinn ini berpusat pada hegemoni gender yang selalu direproduksi oleh Barat dalam film-film khususnya dalam Wolverine dan Deadpool. Quinn menyimpulkan bahwa maskulinitas menjadi bagian yang tidak terpisahkan dalam karya epik film-film barat. 


\section{Landasan Teori}

\section{1. Konsep Superhero}

Superhero merupakan konsep turunan dari istilah hero yang berarti defender atau pembela. Superhero selalu dikaitkan dengan ide-ide kebaikan dan kepahlawanan yang selalu melekat di dalam cerita mereka. Jika istilah hero merupakan kata general yang dipakai kaum strukturalis, maka superhero dikembangkan dalam kerangka postmodernisme yang melihat perkembangan komik dan adaptasinya dalam film. Andrew Hoberek menjelaskan superhero sebagai "a postmodern burlesque of seventies culture that combines references to the Golden Age of superhero comics with cameos from both real-life celebrities and fictional characters" (Hoberek, 2014: 159). Inilah yang menciptakan dunia superhero harus terpisah dengan pendahulunya.

Arketipe superhero yang digambarkan dalam legenda merupakan seseorang yang sangat kuat, yang berjuang melawan rintangan yang berat demi menaklukkan atau mengalahkan kejahatan seperti naga, monster, ular dan lain sebagainya. Citra superhero yang baik dianggap sebagai kepribadian yang ideal (Feist, 2008: 116-117). Menentukan sebuah karakter superhero merupakan asumsi yang tidak mudah dilakukan melihat kemiripan dalam beberapa myth-nya (King, 2016: 34-35). Beberapa orang akan kebingungan menentukan siapakah superhero diantara Luke Skywalker, Batman, Buzz Lightyear. Maka dari itu perlu identifikasi terhadap apa definisi yang pas untuk superhero.

Richard Reynolds (1994: 16) memeperkenalkan tujuh atribut superhero, yaitu:

1. Superhero ditandai sebagai "yang tereksklusi" dari masyarakat. Ia sering mencapai kedewasaan tanpa memiliki hubungan dengan orang tuanya.

2. Beberapa superhero tampak seperti dewa di Bumi. Superhero lain dari kekuatan yang lebih rendah akan bersatu mudah dengan dewa yang membumi ini.

3. Pengabdian sang superhero kepada keadilan bahkan mengesampingkan pengabdiannya pada hukum.

4. Sifat luar biasa dari superhero akan kontras dengan keadaan biasa di sekelilingnya.

5. Sifat luar biasa dari superhero akan kontras dengan sifat biasa dari alter-egonya. Beberapa hal tabu tertentu akan mengatur tindakan alter- ego ini.

6. Meskipun pada akhirnya di atas hukum, para superhero mampu melakukannya patriotisme dan kesetiaan moral yang besar kepada negara.

7. Cerita superhero adalah mitos; menggunakan sains dan mitos tanpa pandang bulu untuk membuat heran terhadap audiens. 


\section{2. Konsep Anti-hero}

Anti-hero merupakan tokoh utama dalam sebuah karya yang memiliki problematika kompleks dan dipandang sangat berbeda dengan karakter superhero ada umumnya. Karakterkarakter semacam ini memiliki kekurangan dalam hal moralitas dan idealisme serta menolak kode etik superhero yang konvensional. Mereka memiliki pendirian tentang apa yang disebut dengan kebaikan dan berbuat baik untuk dunia yang mereka percayai (atau dunia yang dikutuk karena menciptakan mereka).

Sejarah kepopuleran anti-hero dapat dilacak dalam karya para tokoh eksistensialis seperti The Metamorphosis dari Frank Kafka (Robertson, 2012: 30-74) dan La Nausee (Nausea) karya Jean Paul Sartre (1969). Dalam kesusastraan Amerika, anti-hero muncul pada 1960-an. Namun, pada saat itu karakter anti-hero merupakan karakter yang teralienasi dalam plot-nya, tidak mampu berinteraksi dengan baik dalam cerita tersebut. Hingga kemudian karakter-karakter ini ditulis kembali dengan formula dan myth yang berbeda yang kemudian menciptakan kekuatan dari anti-hero tersebut.

Namun, kritik kontemporer cenderung mengabaikan anti-heroik sebagai bentuk yang berkembang, dan bukannya berkonsentrasi pada gagasan yang muncul seperti "Metafiksi", "Surfiction" (bentuk fiksi refleksif yang sering berfokus pada struktur), dan "humor hitam" (cara penulisan baru yang dilambangkan dengan inovasi formal dan perpaduan komedi dan ironi berat) (Simmons, 2008: 1). Gagasan ini muncul pada 1960- an di Amerika Serikat yang pada waktu itu belum melihat gambaran yang lebih luas dari konsep anti-hero.

Kritik tersebut sudah tidak berlaku lagi saat ini ditandai dengan kemunculan berbagai dinamisasi karakter dan berbagai karya adaptasi monumental. Istilah absurd hero tidak tepat disematkan kepada karakter anti-hero karena keduanya bertolak belakang. Apa yang para kritikus maksud tentang absurd adalah karena melihat keterputusan total antara sistem sosialpolitik laki-laki di dunia ini dan sistem yang lebih tinggi menjadi sebuah keputusan pasif (Simmons, 2008: 2). Dalam realitas perjalanan anti-hero selama puluhan tahun, karakter ini memiliki instrumen fundamental yang kuat sehingga terasa aneh jika perannya diabaikan.

Dengan melihat konsep yang diberikan Campbell (1949: 358-362) Simmons (2008: 1-2) dan Garrett (2007: 1-20), dapat disimpulkan bahwa ada tiga bahasan utama dalam analisis karakter anti-hero:

1. Mengeksplorasi sisi gelap karakter untuk mendapatkan gambaran relevan antara jati diri superhero konvensional serta realitas kepahlawanan yang berkembang di dalam masyarakat modern. 
2. Mengaburkan makna "baik" dan "jahat", dimana perspektif semacam ini kerap kali dimunculkan dalam beberapa karya sastra. Terlebih, dalam karya yang memiliki nilai politis dan ideologis. Dalam hal ini, karakter harus dipandang sebagai mereka yang berada dalam wilayah abu-abu.

3. Melihat dari perspektif yang berbeda. Gagasan ini sangat tepat menggambarkan bagaimana tatanan dunia saat ini yang cenderung berubah-ubah. Melihat stagnansi karakter superhero tentu sangat membosankan sehingga peran anti- hero terlihat jelas dan dapat diterima oleh kalangan luas.

\subsection{Teori Hegemoni Antonio Gramsci}

Pemikiran politik dan budaya Gramsi terbentuk selama periode kelam: hancurnya perlawanan kelas pekerja di Eropa, kegagalan pergerakan kelas pekerja di Italia dan perjuangan mereka terhadap pemilik pabrik, serta pergolakan Italia di bawah fasisme Mussolini (Jones, 2006: 42). Sebagai salah satu pemikir Marxis yang paling inovatif dan penting, Gramsci menjadi sosok sentral dalam pembahasan hegemoni. Analisis Gramsci terhadap hegemoni melampaui konsep "dominasi” yang dianggap gagal dalam memahami sistem kerja subordinat terhadap kekuatan yang berkuasa (Femia, 1981: 1).

Berawal dari pemikir Italia tradisional, Machiavelli hingga Pareto - antara "kekuatan” dan "persetujuan" - Gramsci menjelaskan bahwa supremasi grup sosial menjadi manifestasi dalam dua cara: dominasi (dominio), paksaan (coercion), serta kepemimpinan moral dan intelektual (Aurelio dalam Femia, 1981: 4). Dalam hal ini episteomologi Gramsci terhadap hegemoni yaitu:

Hegemony is the predominance obtained by consent rather than force or one class or group over other classes. And whereas "domination" is realized, essentially, through the coercive machinery of the state, "moral leadership and intellectual" is objectified in, and mainly exercised through, "civil society", the ensemble of educational, religious and associational institutions (Femia, 1981: 23).

Hegemoni Gramsci jauh melampaui konsep Marxis yang memahami ekonomi sebagai pemegang kuasa dalam sebuah peradaban. Kelas pekerja, hanya menjadi yang terdepan dan dominan - yaitu kelas hegemonik - sejauh ia berhasil menciptakan sistem aliansi kelas yang memungkinkannya memobilisasi mayoritas populasi pekerja melawan kapitalisme dan Negara borjuis (Gramsci, 1994: 320). Karena perkembangan historis 
masyarakat Italia, hal ini bukanlah perjuangan murni yang ditimbulkan dalam hal ketidaksetaraan ekonomi. Untuk memimpin kelompok lain dalam populasi pekerja, khususnya kaum tani Italia, gerakan kelas pekerja harus memahami isu-isu yang secara budaya penting bagi kaum tani, dan menjadikannya milik mereka sendiri (Jones, 2006: 45).

Gramsci berusaha membangun teori yang mengakui otonomi, kemandirian, dan pentingnya budaya dan ideologi (Ransome, 1992: 128 \& 138). Gramsci mengambil superstruktur selangkah lebih maju ketika dia membaginya menjadi institusi yang bersifat memaksa (koersif) dan institusi yang bersifat tidak memaksa (non-koersif). Institusi yang bersifat paksaan (koersif) pada dasarnya adalah institusi publik seperti pemerintah, polisi, angkatan bersenjata dan sistem hukum yang dianggap sebagai negara atau masyarakat politik. Sedangkan institusi yang bersifat tidak memaksa (non-koersif) antara lain seperti gereja, sekolah, serikat pekerja, partai politik, asosiasi budaya, klub, dan keluarga yang dianggap sebagai masyarakat sipil (Gramsci, 1976: 12, 238). Bagi Gramsci, masyarakat terdiri dari hubungan produksi serta negara atau masyarakat politik dan masyarakat sipil (Jackson, 1958: 568).

Gramsci menerima analisis kapitalisme yang diajukan oleh Marx dan menerima bahwa perjuangan antara kelas yang berkuasa dan kelas pekerja yang lebih rendah adalah kekuatan pendorong yang menggerakkan masyarakat ke depan (Boggs, 1976: 366-367). Gramsci tidak setuju dengan gagasan yang dikemukakan oleh Marx bahwa kelas penguasa tetap berkuasa semata-mata karena mereka memiliki kekuatan ekonomi. Karena itu, ia memperkenalkan konsepnya sendiri menggunakan ideologi. Ideologi adalah ide atau kepercayaan bersama yang berfungsi untuk membenarkan kepentingan kelompok dominan (Boggs, 1976: 21-36). Gramsci merasa bahwa kekuatan ideologis membuat kelas yang berkuasa tetap berkuasa karena memungkinkan mereka untuk mencuci otak dan memanipulasi seluruh masyarakat.

\section{3. 1. Hegemoni Bahasa}

Dalam kajian hegemoni dan bahasa, Gramsci sejalan dengan Louis Dupre dan Raymond Williams melihat bahasa sebagai produk budaya dan materi dari aktivitas manusia. Ada dua model aturan kebahasaan (gramatika) dalam kaidah Gramsci, yaitu Imminent Grammar dan Normative Grammar. Imminent Grammar merupakan aturan bahasa yang diproduksi dari keseharian manusia yang berasal dari kesadaran. Sedangkan normative grammar dibentuk oleh korporat dan merupakan alat hegemoni dari kekuasaan yang ada (Ives, 2004: 40). 
Bahasa menjadi alat penting sebagai media pelayan fungsi hegemoni. Kekuatan bahasa dapat terjadi apabila bahasa tersebut mampu mengubah keadaan atau situasi tertentu dalam kehidupan masyarakat. Masyarakat yang percaya kekuatan bahasa akan selalu menggunakan bahasa untuk kelangsungan hidupnya. Mereka juga akan tahu bahwa bahasa dapat merubah kualitas kehidupannya. Di masa sekarang ini, penggunaan kebudayaan termasuk bahasa di dalamnya menjadi alat untuk meraih sekaligus mempertahankan kekuasan. Bahasa merupakan salah satu media komunikasi yang paling mendasar sekaligus yang paling efektif untuk menyampaikan ide, gagasan, atau pemikiran kita kepada orang lain. Fungsi bahasa yang semacam ini tentu sejalan dengan fungsi hegemoni. Praktik kebahasaan berguna untuk menunjang praktik hegemoni agar berjalan dengan lancar tanpa ada kekerasan fisik. Penguasa atau kelompok dominan menyampaikan ide yang di dalamnya termuat ideologi melalui diksi dan gaya bahasa yang retoris dan dapat dipahami oleh kelompok yang kita kuasai, sehingga apapun yang kita ucapkan dapat menjadi sebuah kebenaran dan keharusan untuk dilaksanakan.

Praktik kebahasaan yang menghegemoni semacam ini tentu memiliki dampak yang positif dan tidak jarang juga memiliki dampak yang destruktif. Menjadi positif apabila hegemoni tersebut mencoba untuk menghancurkan dominasi kekuasaan yang tidak memperhatikan kepentingan banyak orang. Menjadi negatif apabila hegemoni tersebut mencoba untuk menghancurkan hal-hal positif yang sudah terbangun. Menjadi negatif apabila hegemoni bertujuan untuk melanggengkan kekuasaan yang tidak merakyat, kekuasaan yang meraup keuntungan demi segelintir orang dan bukan banyak orang. Hal-hal seperti ini pun menyebabkan hegemoni menjadi tidak konstruktif pada tatanan sosial masyarakat, namun akan melahirkan masyarakat yang terhegemoni semakin terbelakang dan terpinggirkan.

\section{4. Counter-Hegemoni Antonio Gramsci}

Antonio Gramsci tidak menjelaskan secara eksplisit tentang counter- hegemoni karena sensor yang berlaku saat itu (Gramsci dalam Im, 1991: 126). Bagi Gramsci, momen hegemoni selalu diperebutkan oleh hegemoni alternatif. Hegemoni diciptakan melalui gencarnya perjuangan kelas sehingga harus dimenangkan dan harus dipertahankan (Hall, dkk., 1977: 45-46). Apa yang dimaksud Gramsci adalah semacam konstruksi politik dan ideologis kontra-hegemoni melawan hegemoni borjuis (yaitu kontra aliansi hegemonik 
dengan kelompok sosial lain yang berjuang untuk kepentingan masa depan masyarakat sosialis).

Counter-hegemoni bukan sebuah hegemoni nyata dalam arti sesungguhnya melainkan persiapan-persiapan ekonomis, ideologis, dan politis untuk hegemoni sebelum menggulingkan kapitalisme atau sebelum memenangkan power state (Im, 1991: 142). Dalam proses "memenangkan" ini, ada dua batasan dalam konstruksi counter-hegemoni kaum proletar (Im, 1991: 142-143). Pertama, masyarakat kapitalis modern (yaitu organisasi negara dan asosiasi sipil yang kompleks) yang menjadi dasar bagi hegemoni borjuis yaitu struktur yang kokoh dan rumit untuk memastikan kelangsungan hidup hegemoni borjuis bahkan dalam krisis politik dan ekonomi. Dengan demikian, intervensi politik dan ideologis proletar menjadi sangat sulit. Kedua, dalam masyarakat kapitalis maju, sejumlah kategori orang tidak secara eksklusif ditentukan oleh hubungan produksi kapitalis. Dengan demikian, pekerja menempati semakin sedikit proporsi massa bawahan. Struktur kelas yang berubah telah mengancam posisi istimewa kelas pekerja dalam perjuangan anti-kapitalis. Potensi menggulingkan kapitalisme hanya dilakukan oleh kelas pekerja.

Dengan melihat dua batasan ini, maka strategi dalam membentuk hegemoni kelas pekerja (counter-hegemoni borjuis) adalah "war of position" atau pergulatan posisi, bukan perang pergerakan. Ketika para pekerja menghadapi keberadaan "sistem parit" yang kokoh dalam hegemoni borjuis, dan pada saat yang sama, tidak memiliki potensi yang cukup untuk memimpin perjuangan counter-hegemoni sendirian, mereka terkendala dalam pilihan strategi untuk counter-hegemoni. Serangan frontal melalui strategi "perang pergerakan" bukanlah pilihan yang tepat dalam mengatasi permasalahan ini.

Basis ekonomi dan politik dari hegemoni borjuis dapat dihancurkan dengan konstruksi ekonomi dan politik melalui aliansi pasukan anti-kapitalis. Maka dapat dilihat pertarungan borjuis melawan proletar dengan nyata dalam blok historis dan intelektual.

\section{Metode Penelitian}

Metode penelitian adalah suatu cara ilmiah untuk mendapatkan data yang valid dengan tujuan dapat ditemukan, dikembangkan, atau dibuktikan, suatu pengetahuan tertentu sehingga pada gilirannya dapat digunakan untuk memahami, memecahkan, dan mengantisipasi masalah dalam bidang tertentu. Serangkaian langkah yang dilakukan untuk memperoleh pengetahuan mengenai sebuah objek yang sesuai dengan keberadaan teori yang digunakan dalam sebuah penelitian (Faruk, 2017: 55). 
Metode analisis data yang digunakan dalam penulisan proposal karya ilmiah ini adalah analisis deskriptif kualitatif, dimana peneliti selain mengolah dan menyajikan data, juga melakukan analisis data kualitatifnya. Hal ini dimaksudkan agar dapat mensinergikan beberapa data yang telah didapatkan dengan berbagai literatur maupun data-data lain yang telah dipersiapkan. Dalam menyajikan analisis deskriptif kualitatif, peneliti menggunakan pendekatan interpretif yang mengikutsertakan deduksi data yang diperoleh sebagai bagian dari penelitian kualitatif (Verma dan Mallick, 1999: 29). Data yang telah diperoleh kemudian dianalisa dengan memunculkan beberapa kesimpulan dan hasil temuan berdasarkan usaha penelitian tersebut.

\section{Hasil dan pembahasan}

Bagian ini merupakan pembahasan penelitian. Subbab dalam pembahasan ini akan dibagi menjadi dua, yaitu hegemoni Superhero dan Counter-Hegemoni Deadpool.

\subsection{Hegemoni Superhero}

Hegemoni superhero dalam film ini ditandai dengan kehadiran X-men, sekelompok pahlawan yang terdiri dari para manusia yang mengalami perubahan genetika atau yang disebut sebagai mutant. Kelompok ini didirikan oleh seorang manusia dengan inteligensi yang tinggi dengan kekuatan "cerebro", Prof. Charles Xavier. Dia memiliki peranan yang sangat penting dalam menjaga stabilitas hubungan antara manusia dengan mutant. Pemikiran ideologisnya adalah mutant dapat hidup beriringan dengan manusia. Meski tidak dijelaskan secara detail proses masuknya Wade Wilson ke dalam X-men, namun dapat diasumsikan bahwa Prof. X lah yang membawanya ke markas besar X-men.

Identitas asli seorang Wade Wilson yang merupakan pasukan pembunuh bayaran hingga konfrontasinya dengan Wolverine (X-men Origin: Wolverine, 2009) membuat Professor X atau Charles Xavier memerintahkan Colossus dan Negasonic Teenage Warhead untuk menjaga Deadpool.

Colossus: "I've given Deadpool every chance to join us, but he'd rather act like a child. A heavily-armed child. When will he grow up and see benefits of becoming X-Men (Deadpool, 2016: 00:09.34 - 00.09.46).

Colossus mengibaratkan X-men sebagai komunitas dari para pahlawan (mutant) yang baik karena memberikan perlindungan terhadap manusia yang terlahir sebagai mutant dan menjaga kedamaian di antara manusia dan mutant. Disinilah peran dari Colossus yang ingin 
mempertahankan hegemoni superhero yang selalu membela kebenaran. Bagi Colossus dan kolega di X-men, mempertahankan organisasi berarti mencerminkan sikap dari seorang superhero.

Namun ada pertentangan sikap yang ditunjukkan oleh Wade Wilson atau Deadpool. Dia merasa menjadi bagian dari X-men namun tidak bisa mengubah apapun. Baginya, menjadi superhero tidaklah penting apakah berada dalam kendali organisasi atau membentuk tim sesuai dengan yang dia butuhkan. Deadpool menjadi karakter yang menekan terhadap hegemoni yang berlaku dalam universe-nya (dunia).

Kedua prinsip diatas menunjukkan hegemoni kepahlawanan dalam film ini. Menjadi pahlawan selalu identik dengan konvensi masyarakat yang menganggap bahwa pahlawan merupakan sosok hebat yang selalu melindungi dan membela yang lemah (Garrett, 2012: 4). Konsep ini kemudian menjadi ideologi yang tidak terbantahkan dalam struktur sosial kemasyarakatan. Kemudian hal ini menciptakan asumsi baru dimana siapa saja yang tidak menjadi bagian dari superhero berarti menjadi musuh bagi mereka.

Colossus: "Is that you, Wade?! I knew you'd see error of ways!"

Deadpool: "Yep, that's me, seeing the error of my ways! I just need an itty bitty favor in return!” (Deadpool, 2016: 00.01.18).

Hegemoni superhero selanjutnya dalam film ini ditunjukkan oleh Colossus. Dia menganggap Deadpool selalu melangkah ke arah yang salah. Colossus menilai Deadpool tidak memiliki kepemimpinan (leadership) yang baik sebagaimana superhero pada umumnya. Kepemimpinan ini sangat dibutuhkan oleh hegemon karena menunjukkan bagaimana supremasi mereka atas kaum hegemonik. Superioritas inilah yang menciptakan hegemoni superhero tersebut dapat bertahan lama dan bahkan mengalahkan pemerintahan Amerika Serikat itu sendiri (Costello, 2009: 73-80).

\section{2. Counter-hegemoni Deadpool}

Untuk menciptakan hegemoni baru yang menggeser keberadaan hegemoni yang telah ada, maka Deadpool memiliki beberapa instrumen yang sangat fundamental.

\section{2. 1. Kecerdasan (intelligence)}

Kecerdasan yang dimiliki oleh Deadpool menjadi alat yang digunakannya dalam mengubah persepsi masyarakat tentang "pahlawan yang melakukan kebaikan”. Kecerdasan Deadpool sebagai instrumen counter-hegemoni dapat dibagi menjadi tiga bagian: 


\section{A. Kebahasaan (Merc' With Mouth)}

Seperti yang dikatakan oleh Gramsci, counter-hegemoni terkait dengan persiapan yang dilakukan dalam menghancurkan eksistensi hegemoni yang telah ada serta mengubahnya dengan hegemoni baru. Bahasa dapat menjadi alat yang signifikan karena merupakan alat komunikasi yang menjadi fundamental dalam masyarakat (Ives, 2004: 1820).

Deadpool dikenal dengan rating $\mathrm{R}$ karena unsur-unsur yang tabu di dalam masyarakat yang diungkapkan secara eksplisit. Bahasa yang digunakan lebih condong ke bahasa yang kasar dan sering menyinggung karakter lain. Dia menamai sendiri cara berargumentasinya dengan sebutan "merc' with mouth".

Deadpool: "Can I get some fries with that shake-shake boobie? If looks could kill you would be an uzi”" (Deadpool, 2016: 00:06.37 - 00.06.42).

Deadpool: “Ten. Shit! Nine. Fuck! Eight. Shit-fuck!” (Deadpool, 2016: 00:11.30-00.11.35).

Ini merupakan contoh bagaimana cara berkomunikasi yang diterapkan oleh Deadpool. Dalam karakter alter ego-nya, seagai Wade Wilson, gaya bahasa seperti ini tetap dipertahankan. Seperti dalam percakapannya dengan Weasel, karakter yang memperkenalkan nama Deadpool kepada Wilson.

WEASEL : Wade Wilson, Patron Saint of the Pitiful. What can I get you? WADE: I'd love a blow-job.

WEASEL: We got that in common.

WADE :The drink, moose-knuckle. But first... (Deadpool, 2016: 00:17.58 00.18.06)

Bahasa yang digunakan oleh Deadpool merujuk pada imminent grammar, yaitu sistem kebahasaan yang terjadi dengan sendirinya tanpa ada campur tangan korporasi (Ives, 2004: 40). Ini menunjukkan kesadaran Deadpool tanpa harus mengikuti sistem kebahasaan yang dikontrol oleh korporasi (normative grammar). Karena dalam konsepsi Gramsci mengikuti korporasi berarti tunduk pada hegemoni yang ada sehingga counter-hegemoni urung dijalankan.

Dengan demikian, Deadpool memenuhi ekspektasi masyarakat umum yang 
menginginkan karakter yang lebih dekat dengan kehidupan mereka, tidak hanya sebagai simbol yang bahkan mendekati dewa. Masyarakat-lah salah satu komponen pembentuk Superhero (Garrett, 2012: 7). Tanpa andil dari masyarakat maka tidak akan ada pergeseran nilai ideologis demi menggulingkan hegemoni.

\section{B. Break the Fourth Wall}

Ada kemiripan yang tampak jelas dipertahankan dalam adaptasi film Deadpool. Deadpool merupakan karakter yang disebut memiliki "medium awareness" dimana menciptakan kesadaran yang "aneh". Karakter ini bahkan tahu bahwa dia adalah tokoh fiksi yang mampu berbicara dengan penontonnya. Inilah yang disebut dengan break the fourth wall.

Deadpool: "Oh, hello, Deadpool here. You may be wondering whose balls I had to fondle to get my own movie. Rhymes with 'Polverine.' Couple'a smooth criminals. In a word, gorgeous... Surprisingly little hair down there... It's a jungle down there.. Thick underbrush... Anyway, I smell Oscar. The suit's gonna match the carpet. Now... places to be... faces to fix... bad guys to kill..." (Deadpool, 2016: 00:06.45 - 00:07.08)

Percakapan ini adalah antara Deadpool dengan penonton. Dalam mempersiapkan instrumen counter-hegemoni terhadap sistem superhero, break the fourth wall dapat dijadikan unsur yang kuat. Terlebih, walaupun dalam keadaan berinteraksi dengan penonton, Deadpool tetap sadar dan waspada terhadap sekelilingnya. Karakteristik break the fourth wall tidak dimiliki semua karakter. Dengan perbedaan karakteristik menguatkan perang posisi Deadpool terhadap superhero konvensional.

\section{3. Kekuatan dan Kemampuan Deadpool}

Untuk melawan hegemoni yang telah eksis, sangat tidak bijaksana jika Deadpool digambarkan seperti superhero pada umumnya. Karena sifat alamiah sebagai anti-hero, Deadpool dinarasikan dengan karakter yang memiliki banyak sekali kemampuan manusia super. Instrumen superhuman ini sangat penting karena Deadpool akan meng-counter superhero yang sebagian besar dari mereka memiliki kemampuan luar biasa dan telah menjadi bagian dari tatanan masyarakat beserta sistem yang berkuasa.

\section{A. Regenerative Healing Factor (kemampuan meregenerasi tubuh)}

Kemampuan ini dia dapatkan berkat rekayasa genetika yang dilakukan Ajax (Francis) 
terhadap Wade Wilson yang sebenarnya akan direkrut sebagai Weapon X. Dengan kemampuan ini tubuh Deadpool dapat dengan spontan merespon kerusakan yang terjadi (karena tembakan, tusukan, dan lain-lain) sehingga membuatnya hampir mustahil untuk dilawan. Meski bukan satu-satunya pemilik kemampuan healing - Wolverine juga dibekali kemampuan ini - namun healing factor ini sangat berguna untuk menempatkannya sebagai karakter yang tidak sembarangan untuk dihadapi.

\section{B. Foreign Chemical Resistance (ketahanan terhadap senjata biokimia)}

Biokimia telah menjadi sebuah fenomena tersendiri sebagaimana yang terjadi di dunia ini. Karakter Deadpool seakan-akan mengisyaratkan bahwa biokimia bukanlah sesuatu yang patut dikhawatirkan secara berlebihan. Komponen ini menjadi sangat krusial karena jauh melewati ekspektasi manusia yang selalu diteror oleh senjara biokimia. Sebuah nilai yang sangat besar bagi karakter yang berjuang demi hegemoni-nya sendiri.

\section{Disease immunity}

Sebagai Deadpool maupun Wade Wilson, tidak ada penyakit yang mampu bertahan lama di tubuhnya. Satu-satunya penyakit yang dia miliki adalah kanker ganas yang timbul akibat rekayasa yang dilakukan oleh Ajax pada tubuhnya. Namun, hal ini yang menjadikan Deadpool lebih dekat dengan masyarakat. Dia menjadi tokoh yang mampu memberi suntikan motivasi kepada mereka yang berjuang untuk kehidupan.

\section{Telepathic immunity}

Siapapun karakter Superhero yang memiliki kemampuan telepati - prof. X hingga Jean Gray sekalipun - tidak akan mampu melakukannya di depan Deadpool. Wilson menganggap pikiran sebagai sebuah privasi dimana tidak boleh ada yang menginterupsi di dalamnya. Kemampuan ini juga imbas dari break the fourth wall.

\section{E. Peak human strength, Superhuman stamina, Superhuman agility}

Jika ada yang mengimbangi Deadpool dalam hal ini tentu saja Superman, Wolverine, Hulk, atau Captain Amerika. Tidak banyak karakter yang memiliki kompleksitas seperti yang ditunjukkan Deadpool dalam filmnya. Selain itu, elastisitas tubuhnya sangat luar biasa sehingga Deadpool seakan tidak memiliki tulang. Kecepatannya mungkin tidak sehebat Quicksilver, namun ketahanan tubuhnya membuat Deadpool mampu berlari tanpa henti. 


\subsection{Senjata (Weapon $X)$}

\section{4. 1. Pedang Katana}

Sebagai seorang mercenary, Deadpool dibekali dengan pedang katana yang ditempa dengan adamantium sebagai hadiah dari perekrut terdahulunya karena dia mampu bertahan dengan rekayasa genetika yang hampir membunuhnya (lihat X-Men Origins: Wolverine: 2009). Wade Wilson sebelum dikenal sebagai Deadpool memang memiliki kemampuan bertarung menggunakan pedang di atas rata-rata. Dia direkrut untuk membantai seluruh mutant. Akan tetapi, ketika dia sadar terhadap keberadannya, pedang katana yang ditempa dari adamantium ini sangat berguna untuk melawan siapapun yang mengganggu kehidupannya, termasuk ideologi yang dia pegang sebagai anti-hero. Para superhero yang lain memlih untuk tidak berkonflik dengan adamantium Deadpool yang kekuatannya setara dengan cakar Wolverine.

Selain sisi praktis tersebut, pedang katana juga menyiratkan asimilasi budaya yang sangat kental. Wade Wilson yang dibesarkan di Amerika Serikat, menjadi tentara elit AS yang kemudian berbelok arah menjadi pembunuh bayaran karena dianggap mewakili keberadaan kawasan bawah (dalam Marvel Universe) yang ternyata memiliki andil yang cukup besar dalam eksistensi Deadpool. Pedang katana merupakan perwujudan kekuatan samurai Jepang yang ditempa dengan adamantium yang berasal dari kawasan Afrika, kerajaan Wakanda. Instrumen ini cukup kuat untuk melawan hegemoni superhero yang bertahan lama.

\section{5. Perlawanan Ideologis}

Perlawanan ideologis yang dilakukan Deadpool sangat krusial serta sangat frontal. Deadpool secara langsung melancarkan psywar terhadap karakter-karakter superhero dalam film ini. Memang, dalam film ini karakter seperti yang disinggung Deadpool hanya menjadi bagian narasi. Namun, efek yang ditimbulkan sangat luas karena beberapa karakter itu bersinggungan dengan Deadpool dalam secara historis.

“...Rhymes with 'Polverine.” (Deadpool, 2016: 00:06.53 - 00.06.56)

Superhero pertama adalah Wolverine, teman baik Prof. X yang merupakan karakter 
dengan rekayasa genetika sempurna dengan adamantium yang melekat pada tubuhnya. Deadpool terlihat seperti tidak senang dengan eksistensi Wolverine yang cukup major dalam film superhero. Terlebih dia pernah berkonfrontasi secara langsung dan merasakan adamantium pada film Wolverine (2012). Sangat sulit melihat siapa yang lebih tangguh antara Deadpool atau Wolverine. Dengan asumsi tersebut, dapat disimpulkan bahwa Wolverine adalah salah satu hegemon yang akan diruntuhkan oleh Deadpool.

Karakter kedua adalah sosok keadilan di dunia Marvel (Marvel Universe) yaitu Daredevil. Karakter ini merupakan tokoh keadilan yang sehari-harinya bekerja sebagai pengacara. Digambarkan sebagai karakter yang tidak bisa melihat (buta), Daredevil berubah menjadi seorang vigilante di malam hari. Tidak ada keterkaitan langsung antara Deadpool dan Daredevil. Namun, ini lebih karena Deadpool merupakan karakter Marvel yang cukup sukses diadaptasi oleh Netflix pada 2015. Resepsi hingga kritik sangat bagus sehingga menciptakan gengsi tersendiri terhadap keberadaan Deadpool yang baru akan memulai debut di jagat Marvel. Maka, sebagai karakter dengan konsep break the fourth wall, Deadpool tidak ingin usahanya melawan hegemoni superhero terpatahkan oleh keberadaan Daredevil (meski banyak yang menganggap bahwa Daredevil juga merupakan anti-hero). Karakter terakhir yang disebut oleh Deadpool adalah Green Lantern (Reese \& Wernick, 2015: 8).

Tidak ada yang lebih mencengangkan daripada penuturan Deadpool tersebut. Green Lantern merupakan karakter yang berasal dari pesaing utama Marvel, DC Comics. Dunia mereka sangat berbeda dengan alur dan konsep yang bertabrakan satu sama lainnya. Deadpool dengan Marvel Universe, sedangkan Green Lantern merupakan karakter kosmik yang perannya adalah sebagai polisi penjaga kedamaian antargalaksi (Campbell, Green Lantern).

Konfrontasi yang diciptakan ini lebih mengarah kepada sosok Ryan Reynolds, pemeran Deadpool yang sebelumnya membintangi film Green Lantern. Film tersebut mengalami kehancuran dari sisi finansial hingga kritik dari para pengamat. Reynolds merasa frustrasi dengan perjalanan film tersebut dari penulisan hingga produksi. "we don't have script or know what we want..." (McGloin, 2016). Hingga pada akhirnya dia memutuskan untuk menggarap sendiri film Deadpool yang sukses di pasaran Internasional.

Jika ditelusuri lebih mendalam, Deadpool sebenarnya merupakan tokoh dengan medium awareness sehingga dia mampu menciptakan bayangan realitasnya sendiri. Konstruksi realitas yang dia ciptakan membuatnya susah untuk ditaklukkan. Namun, di sisi lain Deadpool sering melupakan kepribadiannya sehingga keinginannya untuk membunuh yang selama ini dia tekan menjadi menguap dan semakin parah. Saat mengalami tekanan 
kesadarannya, Deadpool membantai kawanan penjahat tanpa merasakan apapun. Tidak ada kemarahan, sakit hati, kasih sayang, dan sebagainya. Kejadian seperti inilah yang berusaha diantisipasi oleh Colossus maupun Negasonic Teenage Warhead. Meski berlawanan dengan ideologi, keduanya menciptakan stabilitas terhadap kepribadian Deadpool.

Selain serangan ideologis melalui psywar terhadap karakter lain, Deadpool juga meyakini bahwa jalan yang dia pilih sebagai anti-hero merupakan suatu hal yang benar. Dia mengakui superioritasnya dalam hal kekuatan, namun dia menolak steorotip superhero yang melekat padanya.

Deadpool: "You're probably thinking, "My boyfriend said this was a superhero movie, but that guy in the red suit just turned that other guy into a fucking kabab!" Well, I may be super, but I'm no hero. And yeah, technically this is a murder. But some of the best love stories start with a murder. And that's exactly what this is: a love story. And to tell it right, I gotta take you back to long before I squeezed this ass into red spandex (Deadpool, 2016: $00.13 .58-00.14 .25)$

Sebagai Superhero dia terkekang dengan aturan-aturan normatif yang sangat tidak sesuai dengan kepribadian dan latar belakangnya, sementara menjadi anti-hero dia bebas menyuarakan konsepsi keadilan sekalipun di luar konvensi umum superhero, seperti dalam kalimat "but some of the best stories start with a murder..." Colossus dan NTW selalu menghalangi jika Deadpool ingin membunuh penjahat karena menurut mereka menjadi pahlawan berarti mengikuti myth yang berlaku tentang 'pahlawan'; menyerahkan penjahat kepada pihak berwajib. Tetapi disini Deadpool berbicara dengan pengalaman; bahwa keadilan itu ditegakkan dengan tangan sendiri, bukan melalui korporasi semu dimana para penjahat selalu lepas dari tangan hukum.

\section{Simpulan}

Film Deadpool 1 \& 2 menawarkan sebuah myth kepada penikmat genre superhero melalui act of violence dimana pada akhirnya Deadpool memainkan peranan sebagai sang anti-hero. Peran yang dimainkan ini memunculkan sebuah intrik melalui skema perlawanan ideologi terhadap keberadaan superhero ortodoks. Deadpool secara gamblang mencounter supremasi para superhero melalui tindakan, bahasa, hingga kemampuan artifisial yang tidak umum dimiliki oleh para superhero.

Kekuatan Deadpool merupakan upaya mereproduksi hegemoni kepahlawanan yang telah lama bertahan di dunia ini. Perlawanan ini ditandai dengan kecerdasan (intelligence), 
penggunaan bahasa (merc with mouth), break the fourth wall, kemampuan adaptifnya terhadap zat kimia, hingga kemampuan meregenerasi tubuh. Dengan demikian, hegemoni kepahlawanan yang bertahan mengalami resistensi hingga memungkinkan terciptanya myth kepahlawanan dengan nilai-nilai baru yang menghegemoni.

\section{Daftar Pustaka}

Bahlmann, A.R. (2016). The Mythology of Superhero. McFarland

Bobbio, N. (1979). Gramsci and the conception of civil society. Dalam Chantal, M. (Ed.), Gramsci and Marxist Theory (pp. 21-47). London, England: Routledge.

Boggs, C. (1976). Gramsci’s Marxism. London: Pluto

Campbell, J. (1949). The Hero with a Thousand Faces. Princeton, NJ: Princeton University Press.

Costello, M.J. (2009). Secret Identity Crisis: Comic Books and the Unmasking of Cold War America. New York: Continuum.

Donner \& Kinberg. (2003-2019). X-men (film series). United States: 20th Century Fox.

Faruk. (2017). Metode Penelitian Sastra; Sebuah Penjelajahan Awal. Yogyakarta: Pustaka Pelajar.

Feist, Jess \& Feist, Gregory J. (2008). Theories of Personality Seventh Edition. United States of America: The McGraw-Hill Companies, Inc.

Femia, J.V. (1987). Gramsci's Political Thought Hegemony, Consciousness, and the Revolutionary Process. Oxford University Press, USA.

Garrett, S. (2012). The Rise of Anti-Hero. Diunduh dari laman www.characterseven.com pada 20 Mei 2020.

Goddard, Drew. (2009). Daredevil. United States: Marvel Television.

Campbell, Martin. (2011). Green Lantern.United States: Warner Bros. Pictures

Gramsci, A. (1976). Selections from the prison Notebooks. (Ed.). Hoare, Q. London, England: Lawrence and Wishart.

Hall, S., Lumley, B., dan McLennan, G. (1977). “Politics and Ideology: Gramsci.” Working Papers in Cultural Studies.

Hoberek, A. (2014). Considering Watchmen: Poetics, Property, Politics. New Jersey: Rutgers University Press.

Im, H.B. (1991). Hegemony and Counter-Hegemony in Gramsci. Lynne Ryener Publisher. 
Ives, P. (2004). Gramsci's Politics of Language: Enganging the Bakhtin Circle and Frankfurt School. London: Pluto Press.

Jackson, T.J.L. (1985). The concept of cultural hegemony: Problems and possibilities. American historical review, 90, hal. 567-593.

Jones, S. (2006). Antonio Gramsci. New York: Routledge.

Kafka F., Robertson, R. (ed.). (2009). The Metamorphosis and Other Stories (Oxford World's Classics). New York: Oxford University Press

King, Z.H. (2016). Comic book realism: sincerity, ethics, and the superhero in contemporary American literature. Iowa: University of Iowa.

Miller, Tim. (2016). Deadpool. . Los Angeles: $20^{\text {th }}$ Fox Centuries.

Quinn, J. (2021). Deadpool and the complex 'crisis' of masculinity. In A. J. Carranza (Ed.), Our Fears Made Manifest: Essays on Terror, Trauma and Loss in Film, 1998-2019 McFarland \& Company, Inc., Publishers. https://mcfarlandbooks.com/product/ourfears-made-manifest/

Ransome, P. (1992). Antonio Gramsci: A New Introduction. New York: Harvester Wheatsheaf.

Reynolds, R. (1994). Super Heroes: A Modern Mythology. Jackson: University Press of Mississippi.

Simmons, D. (1980). "The Anti-hero in The American Novel: From Joseph Keller to Kurt Vonnegut.”. New York: Palgrave Macmillan.

Sartre, J.P. (1969). Nausea. New York: New Direction Paperbook

Sugiyono. (2009). Metode Penelitian Kuantitatif, Kualitatif dan R\&D. Bandung: Alfabeta.

Verma, G. K; Mallick, K. (1999). "Researching Education: Perspectives and Techniques." Philadelphia: Falmer Press, Taylor \& Francis Inc.

Wellek, Renne Dan Austin Warren. (1990). Teori Kesusastraan (Diterjemahkan. Oleh Melani Budianta). Jakarta: Pustaka Jaya.

Weiner, R.G. (2009). Captain America and the Struggle of the Superhero: Critical Essays. London: McFarland \& Company, Inc., Publishers.

Wulandari, T \& Firmawan, H. (2019). Swearing Analysis of Characters in Deadpool Movie. Journal of Language and Literature, Universitas Gunadarma. Diunduh dari laman https://ejournal.gunadarma.ac.id/index.php/sastra/article/view/2050.

Zikmund, W.G. (1997). Business Research Method. Vancouver: Harcourt Canada. 


\section{Website}

Deadpool. 2016. https://www.boxofficemojo.com/release/rl2588706305/. Diakses pada 19 Mei 2020.

Deadpool. Writers on Working with Ryan Reynolds. Diakses pada 19 Mei 2020.

McGloin, M. 2016. Ryan Reynolds Reflects on Green Lantern; Deadpool Makes Fun. Cosmic Book News. https://cosmicbook.news/content/ryan-reynolds-reflects-greenlantern- Deadpool-makes-fun\#axzz405fuvgB1 diakses pada 20 Mei 2020. Diakses pada 1 Juni 2020. 